\section{RMD Open}

Rheumatic \&

Musculoskeletal Diseases

\title{
Polymyalgia rheumatica-like syndrome from checkpoint inhibitor therapy: case series and systematic review of the literature
}

\author{
Cassandra Calabrese, ${ }^{\oplus 1}$ Laura C Cappelli, ${ }^{2}$ Marie Kostine ${ }^{3}$ Elizabeth Kirchner, \\ Tawnie Braaten, ${ }^{2}$ Leonard Calabrese ${ }^{1}$
}

To cite: Calabrese $\mathrm{C}$, Cappelli LC, Kostine M, et al. Polymyalgia rheumatica-like syndrome from checkpoint inhibitor therapy: case series and systematic review of the literature. RMD Open 2019;5:e000906. doi:10.1136/ rmdopen-2019-000906

- Prepublication history and additional material for this paper are available online. To view these files, please visit the journal online (http://dx. doi. org/10.1136/rmdopen-2019000906).

Received 14 January 2019 Revised 12 March 2019 Accepted 27 March 2019

Check for updates

(C) Author(s) (or their employer(s)) 2019. Re-use permitted under CC BY-NC. No commercial re-use. See rights and permissions. Published by BMJ.

${ }^{1}$ Rheumatic \& Immunologic Disease, Cleveland Clinic, Cleveland, Ohio, USA ${ }^{2}$ Division of Rheumatology, Johns Hopkins School of Medicine, Baltimore, Maryland, USA

${ }^{3}$ Rheumatology Department, Centre Hospitalier Universitaire de Bordeaux, Bordeaux, France

Correspondence to Dr Leonard Calabrese; calabrl@ccf.org

\section{ABSTRACT}

Objective To assess whether the polymyalgia rheumatica (PMR)-like syndrome reported as an immune related adverse event (irAE) from checkpoint inhibitor therapy is consistent with the 2012 European League Against Rheumatism (EULAR)/American College of Rheumatology (ACR) provisional criteria for PMR.

Methods The cases were derived from two sources. Group 1 represents reported cases from three contributing centres. Group 2 was derived from a systematic review of the literature searching for all cases reported as PMR or PMR-like illness associated with checkpoint inhibitor therapy. Cases were assessed for the quality of reporting and then analysed to determine whether they fulfilled the 2012 EULAR/ACR provisional criteria for PMR.

Results A total of 49 patients were included for analysis. Among the entire group, 37 (75\%) were designated 'complete' indicating that they had sufficient data to reliably apply the 2012 EULAR/ACR criteria. 28 (75\%) cases fulfilled complete criteria for PMR. A number of cases also demonstrated some clinical features unusual for idiopathic PMR.

Conclusion This study suggests a high proportion of reported cases of checkpoint inhibitor-related PMR fulfil preliminary criteria for PMR, yet in one quarter clinical details were incomplete making verification problematic. Furthermore, in the absence of a gold standard for the diagnosis of PMR, the relationship of checkpoint inhibitorrelated PMR to the idiopathic form remains unclear.

\section{INTRODUCTION}

Checkpoint inhibitor therapy has caused a paradigm shift in the field of oncology, producing significant survival benefits in patients with an ever-growing list of malignancies. Their use, however, is attended by a spectrum of immune related adverse events (irAEs), both general and rheumatic, which threaten their overall effectiveness. ${ }^{1}$ A critical and presently unanswered question is what proportion of these rheumatic irAEs represent the occurrence of classic rheumatic

\section{Key messages}

What is already known about this subject?

- Polymyalgia rheumatica (PMR) and PMR-like illness have been frequently reported in the form of case reports and small series as immune related adverse events (irAEs) from checkpoint inhibitor therapy (ICI).

- The majority of reports vary in amount of clinical detail and the relationship between the PMR-like entity occurring in the setting of $\mathrm{ICl}$ and de novo PMR remains poorly understood.

What does this study add?

- This study provides the largest cohort of ICl-related PMR events to date; collected from three international centres who are systematically studying such events, as well as from a systematic review of all cases reported in the literature, and analyses their capacity to fulfil preliminary 2012 European League Against Rheumatism/American College of Rheumatology criteria for PMR.

How might this impact on clinical practice?

-While three out of four cases with complete reporting meet existing classification criteria for PMR, one in four do not and many cases have atypical features. More detailed assessments and reporting of future cases in prospective studies are needed.

diseases or, alternatively, represent new clinical variants with potentially different pathogenesis, clinical course and treatment responsiveness. Despite scattered clinical descriptions, ${ }^{2-4}$ little is known about the polymyalgia rheumatica (PMR)-like entity that has been described in the setting of checkpoint inhibitor therapy (ICI). In our experience with rheumatic irAEs we have increasingly encountered patients presenting with PMR-like clinical phenotypes. Traditional PMR still remains a poorly understood syndrome of unknown aetiology and without a diagnostic laboratory test. Clinicians generally rely on the 
Table 1 Provisional classification criteria for PMR scoring algorithm

\begin{tabular}{lll}
\hline Feature & $\begin{array}{l}\text { Points without } \\
\text { ultrasound (0-6) }\end{array}$ & $\begin{array}{c}\text { Points with } \\
\text { ultrasound (0-8) }\end{array}$ \\
\hline Morning stiffness lasting $>45$ min & 2 & 2 \\
Hip pain or limited range of motion & 1 & 1 \\
Absence of RF or ACPA & 2 & 2 \\
Absence of other joint involvement & 1 & 1 \\
$\geq 1$ shoulder with subdeltoid bursitis and/or biceps tenosynovitis and/or & 1 \\
glenohumeral synovitis and $\geq 1$ hip with synovitis and/or trochanteric bursitis & $\mathrm{n} / \mathrm{a}$ & 1 \\
$\begin{array}{l}\text { Both shoulders with subdeltoid bursitis, biceps tenosynovitis or glenohumeral } \\
\text { synovitis }\end{array}$ & \\
\hline
\end{tabular}

Required to apply algorithm: age $\geq 50$ years, bilateral shoulder aching and abnormal C reactive protein (CRP) and/or erythrocyte sedimentation rate (ESR).

A score $\geq 4$ is categorised as PMR without ultrasound and a score of $\geq 5$ is categorised as PMR if ultrasound findings are included. ACPA, anti-cyclic citrullinated peptide antibody; PMR, polymyalgia rheumatica; RF, rheumatoid factor.

presence of a compatible clinical picture combined with the detection of inflammatory markers as well as corticosteroid response as a 'test of treatment' to establish the diagnosis. A joint working group from American College of Rheumatology (ACR) and European League Against Rheumatism (EULAR) described a provisional set of classification criteria for PMR, incorporating select elements of the history and physical exam combined with select laboratory and imaging findings. ${ }^{5}$ It is the purpose of this study to address whether cases of PMR reported as irAEs are consistent with that defined by these current classification criteria. Here, we describe in detail the largest series of patients to date with the PMR-like syndrome in the setting of ICI therapy as well as all previous case reports to determine if they meet the 2012 EULAR/ACR provisional criteria for PMR.

\section{MATERIALS AND METHODS}

Case series: cases from each participating centre (Cleveland Clinic Foundation, Johns Hopkins University, University Hospital of Bordeaux) were prospectively collected from ongoing cohorts extending from February 2015 to present. Data were collected on age, sex, tumour type, checkpoint inhibitor, presence or absence of elevated acute phase reactants, bilateral shoulder aching, morning stiffness $>45 \mathrm{~min}$, hip pain, rheumatoid factor (RF)/anti-cyclic citrullinated peptide antibody (ACPA) and presence of other joint involvement (table 1). The diagnoses of PMR were based on expert opinion of the evaluating rheumatologists, and clinical judgement was used to determine whether PMR was attributable to ICI.

A systematic literature search was performed in PubMed and Ovid Embase using the search terms 'polymyalgia rheumatica' (MESH) OR 'polymyalgia rheumatica' AND 'immunotherapy' OR 'checkpoint inhibitor therapy' through 1 April 2018. The equivalent Emtree terms were used in the Embase search.

In 2012, EULAR and ACR published consensus-based classification criteria for PMR. ${ }^{5}$ Details of eligibility and the scoring system are included in table 1 . A score of $\geq 4$ has $68 \%$ sensitivity and $78 \%$ specificity for identifying PMR. There are additional points for musculoskeletal ultrasound findings (shoulders or hips), which increase the specificity to $81 \%$, but are not required for classification. We appraised among the reported cases how many provided adequate information to apply the EULAR/ACR criteria for PMR. These were designated as 'complete.' The remainder were designated as 'incomplete.'

\section{RESULTS}

A total of 49 patients were included for analysis: nine cases from Cleveland Clinic, four cases from Johns Hopkins University, seven cases from University Hospital of Bordeaux (table 2) and 29 cases found by systematic review (online supplementary table 3 ). Of all cases combined, $37(75 \%)$ were designated 'complete.' The remaining $12(25 \%)$ were designated 'incomplete' and thus censored from further evaluation. Of the 20 patients from the three centres, 18 had complete data $(90 \%)$, compared with $62 \%$ from the systematic review. Within the complete group, 28/37 (75\%) fulfilled EULAR/ACR criteria for PMR. Eight patients also met imaging criteria. The main reason for failure to meet criteria was the presence of other joint involvement-most commonly knees, followed by hands and elbows. Of patients from the three centres, $9 / 20(45 \%)$ had involvement of other joints, 6/20 (30\%) had normal inflammatory markers and five patients had profound morning stiffness, with explosive onset noted in one individual; within hours of the patient's first ICI infusion with pain and stiffness preventing independent transfer from bed. Two patients had low-positive RF and one had low positive ACPA. One case described a patient with remitting seronegative symmetrical synovitis with pitting oedema. Of 20 patients from our three centres, the median time to onset of PMR symptoms was 12 weeks after start of ICI; tumour was active in $8 / 20(40 \%)$. In the whole group, the specific ICI was reported in 33/49 (67\%) cases: 12 were exposed to nivolumab, five to combination ipilimumab/nivolumab, nine to pembrolizumab, four to ipilimumab, two to 
Table 2 Characteristics of 20 patients from three centres

\begin{tabular}{|c|c|c|c|c|c|c|c|}
\hline Patient & Age/ Sex & Tumour type & $\begin{array}{l}\text { Checkpoint } \\
\text { inhibitor }\end{array}$ & $\begin{array}{l}\text { Fulfilled } \\
\text { EULAR/ACR } \\
\text { classification } \\
\text { criteria* }^{*} \\
\end{array}$ & $\begin{array}{l}\text { Unfulfilled } \\
\text { criteria }\end{array}$ & $\begin{array}{l}\text { Atypical } \\
\text { features }\end{array}$ & Treatment \\
\hline \multicolumn{8}{|c|}{ Cleveland Clinic Foundation, Cleveland, Ohio, USA } \\
\hline 1 & $63 \mathrm{M}$ & $\mathrm{RCC}$ & Nivolumab & No; five points & $\begin{array}{l}\text { Acute phase } \\
\text { reactants }\end{array}$ & & $\begin{array}{l}\text { Prednisone } 40 \mathrm{mg} \text {; } \\
\text { tocilizumab } 162 \mathrm{mg} \\
\text { q2 weeks }\end{array}$ \\
\hline 2 & $69 \mathrm{M}$ & Melanoma & $\begin{array}{l}\text { Ipilimumab/ } \\
\text { nivolumab }\end{array}$ & Yes; six points & & $\begin{array}{l}\text { Sicca } \\
\text { symptoms; } \\
\text { antinuclear } \\
\text { antibody } \\
1: 1280 \text {, anti- } \\
\text { Sjogren's- } \\
\text { syndrome- } \\
\text { related antigen } \\
\text { A >8 IU }\end{array}$ & Prednisone 30 mg \\
\hline 3 & $79 \mathrm{M}$ & Melanoma & $\begin{array}{l}\text { Ipilimumab/ } \\
\text { nivolumab }\end{array}$ & $\begin{array}{l}\text { Yes; seven } \\
\text { points† }\end{array}$ & & $\begin{array}{l}\text { Sicca } \\
\text { symptoms }\end{array}$ & Prednisone $20 \mathrm{mg}$ \\
\hline 4 & $57 \mathrm{M}$ & Melanoma & Pembrolizumab & No; three points & $\begin{array}{l}\text { Acute phase } \\
\text { reactants; RF } \\
35 \mathrm{IU} / \mathrm{mL} \text {; knee } \\
\text { involvement }\end{array}$ & & Prednisone $60 \mathrm{mg}$ \\
\hline 5 & $60 \mathrm{M}$ & Melanoma & Pembrolizumab & No; three points & $\begin{array}{l}\text { RF } 45 \text { IU/ } \\
\text { mL; knee } \\
\text { involvement }\end{array}$ & & Prednisone $60 \mathrm{mg}$ \\
\hline 6 & $66 \mathrm{M}$ & Melanoma & Nivolumab & Yes; five points & $\begin{array}{l}\text { Hand } \\
\text { involvement }\end{array}$ & & $\begin{array}{l}\text { Prednisone } 20 \text { mg; } \\
\text { methotrexate }\end{array}$ \\
\hline 7 & $69 \mathrm{~F}$ & $\mathrm{RCC}$ & Nivolumab & Yes; five points & $\begin{array}{l}\text { Hand } \\
\text { involvement }\end{array}$ & & $\begin{array}{l}\text { Prednisone } 10 \mathrm{mg} \text {; } \\
\text { tocilizumab } 162 \mathrm{mg} \\
\text { q2 weeks }\end{array}$ \\
\hline 8 & $66 \mathrm{M}$ & $\mathrm{RCC}$ & $\begin{array}{l}\text { Durvalumab; } \\
\text { tremilimumab }\end{array}$ & Yes; five points & $\begin{array}{l}\text { Hand } \\
\text { involvement }\end{array}$ & & Prednisone $20 \mathrm{mg}$ \\
\hline 9 & $72 \mathrm{~F}$ & $\mathrm{RCC}$ & Avelumab & Yes; four points & $\begin{array}{l}\text { Acute phase } \\
\text { reactants; } \\
\text { hand and knee } \\
\text { involvement }\end{array}$ & & Prednisone 20 mg \\
\hline \multicolumn{8}{|c|}{ Johns Hopkins University, Baltimore, Maryland, USA } \\
\hline 10 & $66 \mathrm{M}$ & $\begin{array}{l}\text { Lung } \\
\text { adenocarcinoma }\end{array}$ & Pembrolizumab & No; six points & $\begin{array}{l}\text { Shoulder } \\
\text { aching }\end{array}$ & & Prednisone $20 \mathrm{mg}$ \\
\hline 11 & $63 \mathrm{~F}$ & $\begin{array}{l}\text { Poorly } \\
\text { differentiated } \\
\text { carcinoma with } \\
\text { squamous } \\
\text { features }\end{array}$ & Durvalumab & Yes; six points & & & $\begin{array}{l}\text { Prednisone } 15 \mathrm{mg} \text {; } \\
\text { hydroxychloroquine }\end{array}$ \\
\hline 12 & $59 \mathrm{~F}$ & Melanoma & Nivolumab & Yes; six points & & & $\begin{array}{l}\text { Prednisone } 7.5 \mathrm{mg} \text {; } \\
\text { bilateral trochanter } \\
\text { injections }\end{array}$ \\
\hline 13 & $76 \mathrm{M}$ & $\begin{array}{l}\text { Merkle cell } \\
\text { carcinoma }\end{array}$ & Nivolumab & $\begin{array}{l}\text { No; four } \\
\text { points }\end{array}$ & & & \\
\hline \multicolumn{8}{|c|}{ Centre Hospitalier Universitaire, Bordeaux, France } \\
\hline 14 & $81 \mathrm{M}$ & Melanoma & Pembrolizumab & No; five points & $\begin{array}{l}\text { Acute phase } \\
\text { reactants; knee } \\
\text { involvement }\end{array}$ & & Prednisone $10 \mathrm{mg}$ \\
\hline 15 & $74 \mathrm{M}$ & Melanoma & Pembrolizumab & $\begin{array}{l}\text { Yes; seven } \\
\text { points† }\end{array}$ & & & Prednisone $15 \mathrm{mg}$ \\
\hline 16 & $59 \mathrm{M}$ & Melanoma & Pembrolizumab & $\begin{array}{l}\text { No; seven } \\
\text { points† }^{\star}\end{array}$ & $\begin{array}{l}\text { Acute phase } \\
\text { reactants }\end{array}$ & & Prednisone $10 \mathrm{mg}$ \\
\hline 17 & $65 \mathrm{~F}$ & NSCLC & Nivolumab & $\begin{array}{l}\text { No; seven } \\
\text { points† }\end{array}$ & $\begin{array}{l}\text { Acute phase } \\
\text { reactants }\end{array}$ & & Prednisone 15 mg \\
\hline
\end{tabular}

Continued 
Table 2 Continued

\begin{tabular}{|c|c|c|c|c|c|c|c|}
\hline Patient & Age/ Sex & Tumour type & $\begin{array}{l}\text { Checkpoint } \\
\text { inhibitor }\end{array}$ & $\begin{array}{l}\text { Fulfilled } \\
\text { EULAR/ACR } \\
\text { classification } \\
\text { criteria* }^{*}\end{array}$ & $\begin{array}{l}\text { Unfulfilled } \\
\text { criteria }\end{array}$ & $\begin{array}{l}\text { Atypical } \\
\text { features }\end{array}$ & Treatment \\
\hline 18 & $63 \mathrm{M}$ & NSCLC & Nivolumab & Yes; six points & & $\begin{array}{l}\text { Resolved with } \\
\text { NSAIDs alone }\end{array}$ & NSAIDs \\
\hline 19 & $74 \mathrm{M}$ & $\mathrm{RCC}$ & $\begin{array}{l}\text { Ipilimumab/ } \\
\text { nivolumab }\end{array}$ & Yes; five points & $\begin{array}{l}\text { Hand } \\
\text { involvement }\end{array}$ & & Prednisone $10 \mathrm{mg}$ \\
\hline 20 & $77 \mathrm{~F}$ & Melanoma & Pembrolizumab & Yes; six points $†$ & Hip pain & & Prednisone $15 \mathrm{mg}$ \\
\hline
\end{tabular}

All patients had complete reporting to allow application of the EULAR/ACR classification criteria.

${ }^{*}$ A score of four or more is needed for PMR classification without ultrasound, and a score of five or more if ultrasound is included. †Met ultrasound criteria.

ACR, American College of Rheumatology; EULAR, European League Against Rheumatism; NSAIDs, non-steroidal anti-inflammatory drugs; NSCLC, non-small cell lung cancer;PMR, polymyalgia rheumatica; RCC, renal cell carcinoma.

durvalumab and one to avelumab. The remaining 16 cases were treated with anti-PD-1/L1 therapy.

Among the original group of 49, $46(94 \%)$ received glucocorticoids (GC) as initial treatment for rheumatic irAE. The dose and duration were heterogeneous but the majority of patients responded to $\mathrm{GC}$ alone, in doses ranging from prednisone $7.5 \mathrm{mg}$ to $60 \mathrm{mg}$ daily. 17/46 (37\%) of patients required more than $20 \mathrm{mg}$ of prednisone daily. Three patients responded to non-steroidal anti-inflammatory drugs alone. Two patients ultimately were treated successfully with tocilizumab $162 \mathrm{mg}$ subcutaneously every other week as a GC-sparing agent. Three other patients required disease modifying anti-rheumatic drugs (methotrexate, hydroxychloroquine).

\section{DISCUSSION}

PMR is increasingly recognised as one of the most common inflammatory rheumatic irAEs, based not only on the volume of clinical reports and clinical series, but also in a recent pharmocovigilance study demonstrating a fivefold elevated risk for developing PMR with ICI therapy versus cancer patients not treated with similar immunotherapies. ${ }^{6}$ A reasonable question at present is whether these cases of irAE-PMR represent a disorder identical to the idiopathic form of the disease or rather a new nosologic entity. Answering this is problematic however, given our lack of understanding of its etiopathogenesis and the absence of any highly specific diagnostic test. Given these obstacles, the EULAR/ACR classification criteria provide a logical starting point to address whether ICI-related PMR is similar or different.

Overall our data suggest a mixed picture. In our combined series $25 \%$ of reported cases supplied insufficient data to apply the current classification criteria while of the remaining cases with complete reporting, $75 \%$ of those met classification criteria but frequently contained atypical features which would suggest that in these cases may represent a different entity. It should be noted that a number of atypical features (synovitis, positive serology for rheumatoid arthritis) were disqualifying.
Another atypical feature is a more severe presentations than generally encountered in classical PMR.

Another clinically relevant finding that may also speak to differences in pathogenesis between traditional PMR and ICI-induced PMR is that, 37\% of cases required more aggressive therapy with GC than is traditionally used to treat PMR. With regards to the initial GC dose, the heterogeneity and higher initial doses may reflect clinicians' lack of confidence in diagnosis; some patients may have had GCs initiated by their oncologist, prior to referral to rheumatology. Among our multi-centre case series, $20 \%(4 / 20)$ received a GC-sparing agent, with two cases responding well to the IL-6 inhibitor tocilizumab after failing repeated efforts to reduce GC dose to the standards generally utilised in idiopathic PMR. It has been suggested the rheumatic irAEs differ from other system irAEs in that inflammation may persist, even after cessation of checkpoint inhibitor therapy, and require prolonged treatment. ${ }^{478}$ Notably, both patients from our series who required tocilizumab have required it long term, currently 24 months in one patient. In the literature, tocilizumab has been successfully used to treat inflammatory arthritis from ICI as well as irAEs involving other systems, suggesting a pathogenic role of IL-6 and thus Th17 cells in autoimmunity and the development of irAEs. ${ }^{910}$ Also notable was that seven patients had normal acute phase reactants at the time of PMR diagnosis.

The strengths of the current study include the size of the cohort and collaborative design among three institutions prospectively collecting data on all rheumatic irAEs over the study period. There are, however, several significant limitations, emblematic of many studies published in this early phase of clinical research in the rheumatic irAE era, which deserve mention. The retrospective nature of the current study limits our ability to estimate disease incidence. Case finding may also be potentially confounded by a referral bias, as it is conceivable that some additional patients may have been treated by oncologists without referral to rheumatology and thus may have not been included. In addition, outside of the 20 cases from our own institutions, we are subjected to 
limitations of reporting bias for critical elements of the ACR/EULAR criteria which were unavailable in many cases for those identified via our literature search. It is possible that some of these cases could conceivably be reclassified if additional data were available.

A burning question in the field of irAEs is whether diseases which closely resemble de novo autoimmune disease states are actually examples of the classical forms of such disorders or new entities. Based on our study we believe we have identified a meaningful proportion of cases from our multicentre experience and the extant literature that appear to fall outside of what appears to be reasonable in terms of their overall clinical picture suggesting that at least some may represent a new clinical entity. Moving forward our data underscore the urgency for prospective registry-based studies with uniform assessment and reporting of data.

Contributors All authors contributed planning, data, analysis and drafting of this manuscript.

Funding A portion of the research reported in this publication was supported by the National Institute of Arthritis and Musculoskeletal and Skin Diseases of the National Institutes of Health under award number T32AR048522. The content is solely the responsibility of the authors and does not necessarily represent the official views of the National Institutes of Health.

Competing interests CC speaks for Regeneron/Sanofi. LCC received a research grant from Bristol-Myers Squibb and consults for Regeneron/Sanofi. MK consults for Bristol-Myers-Squibb. TB is a fellow supported by T32 grant. EK consults for Celgene, Horizon, Novartis, Regeneron and speaks for Merck and Sanofi. LC consults for Bristol-Myers-Squibb, Genentech and Astra-Zeneca.

Patient consent for publication Not required.

Ethics approval This study obtained ethics approval through the ethics committees at the Cleveland Clinic (IRB\# 17-575), Johns Hopkins University (\# CIR00041091) and Centre Hospitalier Universitaire (local ethics committee \#CE-GR-2017/007).
Provenance and peer review Not commissioned; externally peer reviewed.

Data sharing statement All data relevant to the study are included in the article or uploaded as supplementary information.

Open access This is an open access article distributed in accordance with the Creative Commons Attribution Non Commercial (CC BY-NC 4.0) license, which permits others to distribute, remix, adapt, build upon this work non-commercially, and license their derivative works on different terms, provided the original work is properly cited, appropriate credit is given, any changes made indicated, and the use is non-commercial. See: http://creativecommons.org/licenses/by-nc/4.0/.

\section{REFERENCES}

1. June $\mathrm{CH}$, Warshauer JT, Bluestone JA. Is autoimmunity the Achilles' heel of cancer immunotherapy? Nat Med 2017;23:540-7.

2. Cappelli LC, Gutierrez AK, Bingham CO, et al. Rheumatic and musculoskeletal immune-related adverse events due to immune checkpoint inhibitors: a systematic review of the literature. Arthritis Care Res 2017;69:1751-63.

3. Suarez-Almazor ME, Kim ST, Abdel-Wahab N, et al. Review: immune-related adverse events with use of checkpoint inhibitors for immunotherapy of cancer. Arthritis Rheumatol 2017;69:687-99.

4. Calabrese C, Kirchner E, Kontzias K, et al. Rheumatic immunerelated adverse events of checkpoint therapy for cancer: case series of a new nosological entity. RMD Open 2017;3:e000412.

5. Dasgupta B, Cimmino MA, Maradit-Kremers $\mathrm{H}$, et al. Provisional classification criteria for polymyalgia rheumatic: a European League against Rheumatism/American College of Rheumatology Collaborative initiative. Ann Rheum Dis 2012;2012:484-92.

6. Salem J-E, Manouchehri A, Moey M, et al. Cardiovascular toxicities associated with immune checkpoint inhibitors: an observational, retrospective, pharmacovigilance study. Lancet Oncol 2018;19:1579-89.

7. Cappelli LC, Gutierrez AK, Baer AN, et al. Inflammatory arthritis and sicca syndrome induced by nivolumab and ipilimumab. Ann Rheum Dis 2017;76:43-50.

8. Smith MH, Bass AR. Arthritis after cancer immunotherapy: symptom duration and treatment response. Arth Care \& Res 2018;0:1-4.

9. Kim ST, Tayer J, Trinh VA, et al. Successful treatment of arthritis induced by checkpoint inhibitors with tocilizumab: a case series. Ann Rheum Dis 2017;0.

10. Stroud CR, Hedge A, Cherry C, et al. Tocilizumab for the management of immune mediated adverse events secondary to PD-1 blockade. J Oncol Pharm Pract 2017;0:1-7. 